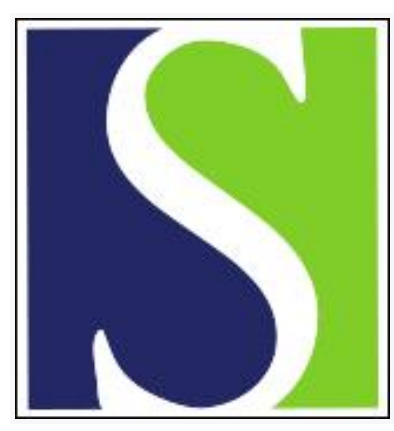

Scand J Work Environ Health 1975;1(1):31-39

https://doi.org/10.5271/sjweh.2863

Issue date: Mar 1975

\title{
Exposure to white spirit. II. Psychological functions.
}

by Gamberale F, Annwall G, Hultengren M

Key terms: experimental psychology; exposure; psychological function; white spirit

This article in PubMed: www.ncbi.nlm.nih.gov/pubmed/1235855 


\title{
Exposure to white spirit II. Psychological functions
}

by FRANCESCO GAMBERALE, psychologist, GÖREL ANNWALL, B.A., and MAY HULTENGREN, engineer ${ }^{1}$

\begin{abstract}
GAMBERALE, F, ANNWALL, G. and HULTENGREN, M. Exposure to white spirit: Ir. Psychological functions. Scand. $j$, work environ. \& health 1 (1975) $31-39$ The effect of the solvent white spirit on psychological functions, such as perceptual speed, reaction time, short-term memory, numerical ability, and manual dexterity, was studied in two separate series of experiments employing 14 and 8 healthy male students, respectiveiy. Each subject was tested repeatedly in each series in exposure to $625,1,250,1,875$ and $2,500 \mathrm{mg} / \mathrm{m}^{3}$ of white spirit in inspiratory air and under control conditions with exposure to pure air. In another experimental series each subject was tested during exposure to $4,000 \mathrm{mg} / \mathrm{m}^{3}$ of white spirit and under control conditions. Alveolax air samples were taken every fifth minute. No effect on examined functions was observed in the first experimental series. However, a prolonged reaction time and a probable impaired short-term memory was observed in subjects exposed to $4,000 \mathrm{mg} / \mathrm{m}^{3}$. At this concentration of white spirit in inspiratory air an alveolar air concentration was obtained which corresponded to values obtained in exposure to $2,500 \mathrm{mg} / \mathrm{m}^{3}$ during light exercise.

Key words: experimental psychology, white spirit, psychological functions.
\end{abstract}

It was shown in our studies of exposure to toluene, methylchloroform, and styrene $(2,3,4)$ that all these solvents had an adverse effect on the performance capability of exposed subjects. It was found that various intellectual and psychomotor functions were affected by exposure to these solvents in concentrations at: which no symptoms of intoxication were manifest and no subjective distress was noted.

The objective of the present investigation was to study whether or not the central nervous system is affected even by exposure to white spirit. To our knowledge no study has ever been conducted on

1 Work Psychology and Technology Divisions, Department of Occupational Medicine, $\mathrm{Na}$ tional Board of Occupational Safety and Health, Stockholm, Sweden.

Reprint requests to: Tf laborator Francesco Gamberale, Kungl. Axbetarskyddsstyreisen, Arbetsmedicinska avdelningen, Arbetspsylsologiska enheten, Fack, 10026 Stockholm 34, Sweden. the effect of exposure to white spirit on human performance. This is remarkable in view of the widespread use of the solvent.

The present investigation constitutes the second part of a study on human exposure to white spirit. The first part of the study (1) deals principally with the uptake of the substance in the organism.

\section{SUBJECTS}

Fourteen healthy men 18 to 34 years of age were used as subjects. They were either students or employees of the Department of Occupational Medicine.

\section{METHODS}

\section{Experimental design}

'Two series of experiments were performed. In the first experimental series all 14 subjects were divided at random 
into two equally large groups. Subjects in one group were first studied under experimental conditions with exposure to white spirit and then 7 days later with exposure to ordinary atmospheric air. Subjects in the other group were studied in a similar manner but in the reverse order. Trials with exposure or nonexposure were begun at the same time of day for each individual subject. Under experimental conditions subjects were exposed to 625 , $1,250,1,875$, and $2,500 \mathrm{mg} / \mathrm{m}^{3}$ of white spirit in inspiratory air in four continuous 30 minute periods. The gas was produced according to the technique described by Astrand et al. (1). The increase in concentration following each 30 -minute period was made without interrupting exposure. The air-gas mixure was supplied via a breathing valve and a mouthpiece with very low resistance (1). The concentration of white spirit in alveolar air was measured every fifth minute with a gas chromatograph according to the technique described by $A$ strand et al (1).

The study was performed with the subjects sitting in a comfortable chair at a desk. Five performance tests were carried out, always in the same sequence, in the final 20 minutes of each exposure period. At given points in each performance test, the subject's heart rate was recorded with telemetric equipment (Medenik, Honeywell). Under control conditions no white spirit was mixed with the inspiratory air. In other respects all operations and measurements were carried out with the same equipment and in the same manner and chronological order as in the experimental conditions. Thus alveolar air samples were taken every fifth minute.

In the second experimental series eight of the subjects who had participated in the first experimental series were exposed to $4,000 \mathrm{mg} / \mathrm{m}^{3}$ of white spirit in inspiratory air for 50 minutes. During the final 20 minutes of the exposure period, the same performance tests as in the first experimental series were performed. Subjects were also studied under control conditions without exposure to white spirit as in the previous experimental series. Half of the subjects were studied during control conditions 2 days before and half 2 days after the experimental trial. In other respects the second experimental series was performed with the same equipment and technique as in the first series.

In both experimental series certain measures were carried out in order to attain the most identical possible perception of conditions by subjects when exposed or unexposed to white spirit. The presence or absence of white spirit was disguised by the introduction of a cannister containing menthol crystals into the tube to the mouthpiece. Previous studies of solvents had shown that the taste and smell of the solvents were especially noticeable in the transition from inspiration through the mouthpiece to normal breathing by nose and mouth. For this reason the subjects had to continue breathing through the mouthpiece for about 3 minutes after the termination of exposure. Moreover, control conditions were started and ended with a relatively strong smell of white spirit in the mouthpiece.

In both experimental series information was collected on the subjects' perceptions of conditions. Subjects filled in a questionnaire after each experimental session, irrespective of exposure or nonexposure. The questionnaire asked subjects to assess their own conditions with respect to the following six variables: calm/hurried, active/passive, relaxed/tense, well-disw posed/ill-disposed, unaffected/affected and spry/tired. Assessments were facilitated with the aid of a 7-point evaluation scale in which extreme values were defined by opposites and in which the scale value 4 corresponded to a completely normal state for the individual. After having filled in the questionnaires, subjects were asked to describe in their own words the possible presence of any subjective symptoms.

In the second experimental series subjects had to fill in the aforementioned questionnaire also immediately prior to the start of testing, i.e., about 30 minutes after the start of the exposure period. After conclusion of exposure on the second day of trials all subjects were asked whether they had been able to notice any difference between the two conditions with respect to inspiratory air. The objective of the interview was to study the extent to which the menthol camouflage and other measures adopted had been effective. 


\section{Performance tests}

The following tests were performed for both white spirit and pure air in the sequence stated below in both experimental series.

Perceptual speed. The test material consisted of two full pages containing a total of 60 columns of 3 -digit numbers. Subjects were instructed to underline the numbers which were exactly the same as the top number in each column. Four parallel versions of the test were used in the first experimental series, one for each exposure period. Oniy one version of the test was used in the second experimental series. The toluene study provides further details (2). Performance capability was measured as the time taken to complete the test.

Simple reaction time. A stimulus/response panel was placed in a horizontal position on the desk in front of the subject. The subject's wrist and forearm rest. ed on the panel, and fingertips on a pushbutton. The upper arm and forearm formed an angle of approximately $110^{\circ}$ The stimulus consisted of a white lamp placed $30 \mathrm{~mm}$ from the pushbutton. The subject was instructed to respond to the signal from the lamp by pressing the push. button with his fingertips. Reaction time was recorded with the aid of an electronic timer. Stimuli were administered at inter. vals of approximately 10 seconds. An acoustic warning signal was given 3 seconds prior to the administration of each stimulus. Thirty stimuli were given in each trial. Performance was measured as the mean reaction time for the last 20 stimuli given.

Short-term memory. A stimulus/response panel was used. The panel had 15 lamps which also served as switches when touched. The lamps/switiches were located so that they formed three lines and five columns. The distance between adjacent lines and columns was $5 \mathrm{~cm}$. Stimuli (lighting of lamps) and response indication (touching lamps) were administered and recorded electronically. In the test a series of stimuli lasting 1 second each and administered at 1-second intervals was presented on the panel. The subject was instructed to touch the lamps which had been lighted as soon as they received a given signal indicating the series was concluded. No consideration was to be paid to the sequence in which the lamps had been lighted. Subjects were presented with 10 different series, in which the number of stimuli in each series varyed from 5 to 11 . Response data were analyzed according to two criteria: I. the number of correctly reproduced stimuli as a percentage of the total number of stimuli and II. the number of correctly reproduced series as a percentage of the total number of series.

Numerical ability: RT Additions. The same equipment was used as in the prem ceeding test. The two uppermost lines of lamps/switches were supplied with legible numbers from 0 to 9 . The test consisted of a series of stimuli in which each stimulus lasted 0.4 seconds on the panel and was administered at 0.1 -second intervals. Subjects were instructed to add up the numbers assigned to the stimuli as quickly as possible and to indicate the answer with the aid of the number switches. Twenty series were presented to the subject at 2second intervals from the time an answer was given. The sequence for the first 4 and the final 16 series varied at random in the different exposure periods. Performance capability was measured as the mean reaction time for the 16 final series.

Manual dexterity: Wire Spiral. The Wire Spiral consisted of a $2 \mathrm{~mm}$ thick steel wire approximately $100 \mathrm{~cm}$ long which had been twisted into a spiral with both ends attached to a wooden endpiece. Fifteen nuts were threaded onto the wire In the test two metal rods were used to transfer the nuts, one at a time, from one end of the wire to the other. Performance capability was measured as the time taken to transfer all nuts from one end of the steel wire to the other. To prevent performance results from being affected by possible shifts in technique during or between the different tests, the subjects were instructed and trained in performing the test according to a standardized techn nique.

The Identical Numbers, Simple Reaction Time and Wire Spiral tests were used in 


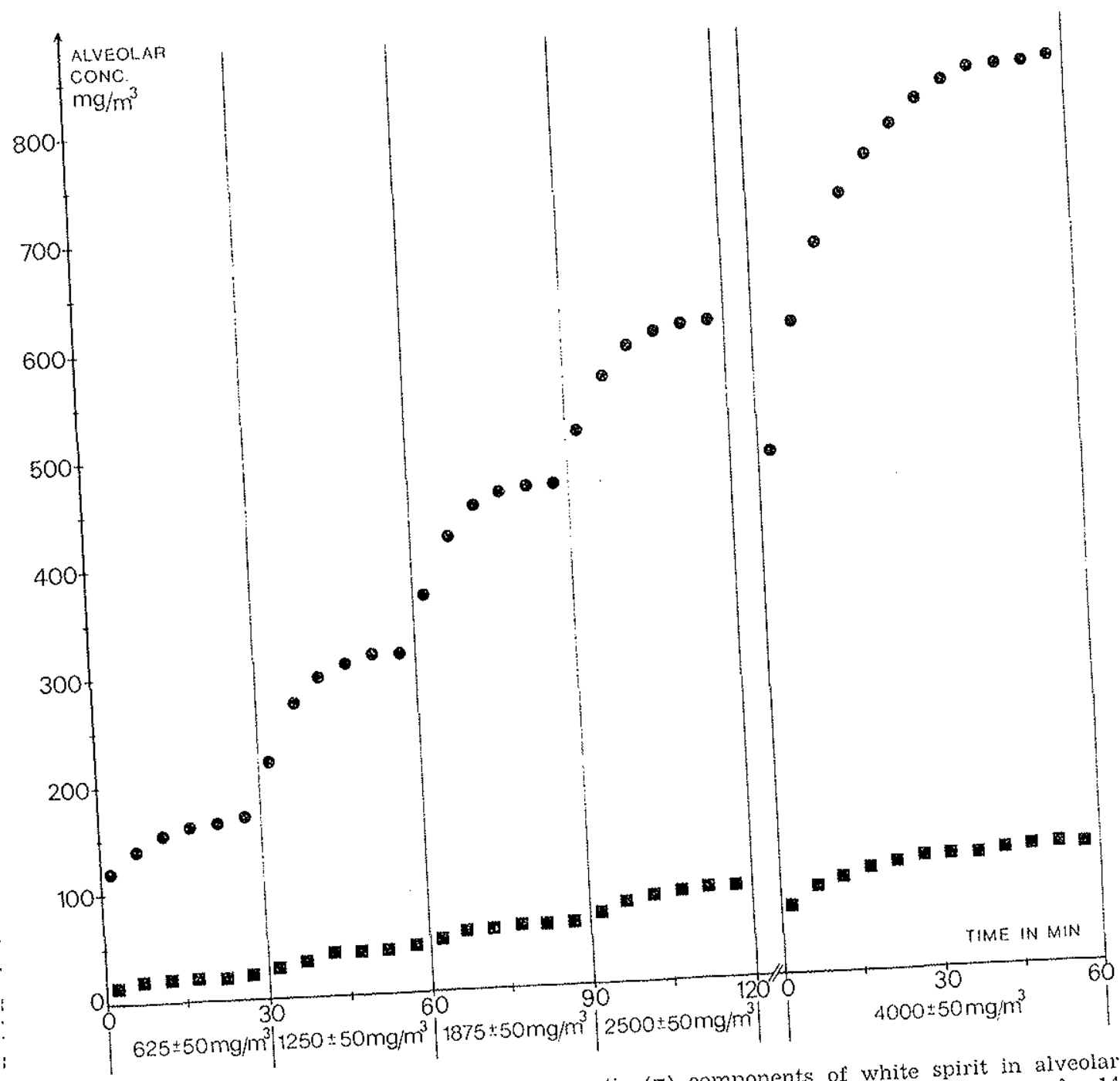

Fig. 1. Concentration of aliphatic ( and aromatic ( components of the to mean values for 14 air in the two expectively.

the previous studies of solvents mentioned The Spokes and Choice Reaction Time tests which were used in these simdies were replaced in the present study by the Short-Term Memory and RT Additions.

\section{RESULTS}

Alveolar air concentration during exposure

The concentrations of aliphatic and aromatic components of white spirit in alveolar air samples taken during experimental conditions are shown in fig. 1 . The symbols in the figure are mean values for the 14 and 8 subjects, respectively, in the wo experimental series. The standard deviations amounted to 20 to $38 \%$ of the respective mean values for the aromatic components and to 14 to $28 \%$ of the respective mean values for the aliphatic components.

The relationship between the concentrain alveolar air and arterial blood of the aliphatic and aromatic components was studied in two of the subjects accord- 
ing to the technique described by Astrand et al. (1). Twenty-four parallel samples of alveolar air and arterial blood were taken during exposure to white spirit in the same concentration and for the same durations as in the first series of psychological experiments. Very high correlations were obtained between concentrations of aliphatic and aromatic components in the alveolar air and arterial blood of both subjects. The relationship between aromatic and aliphatic components in alveolar air is illustrated for one subject in fig. 2.

\section{Subjective perception of conditions}

In the investigation dealing with the up.take of white spirit in the organism (1), 9 of 14 subjects reported being affected by exposure. Their feelings were described with words such as "lightheadedness," "unsteadiness,» «intoxication," and "dizziness." Two of the subjects reported being profoundly affected and described a feeling of being "confused" or sempty-headed." This condition persisted for a few hours after the end of exposure.

The interview conducted in conjunction with the two psychological experimental series disclosed that subjects had been unable to distinguish between experimental and control conditions. Thus the action taken to disguise exposure had been effective. Some impression, mainly consisting of a slight headache and difficulty in concentrating on the tests, was reportm ed by subjects after 14 of 44 test sessions. Subjects had been administered pure air on 5 of these 14 occasions.

Results from the assessment questionnaire filled in by subjects prior to the interviews suggest that white spirit had probably not affected subjective reactions in the psychological experimental series. Also no statistically significant differences could be found between conditions for any of the assessment questionnaire variables nor for different combinations of variables. The statistical analysis was performed using the Wilcoxon matched-pairs signed rank test (5).

In summary there were no pronounced or unequivocal subjective reactions except in conjunction with exposure during physiological experiments.
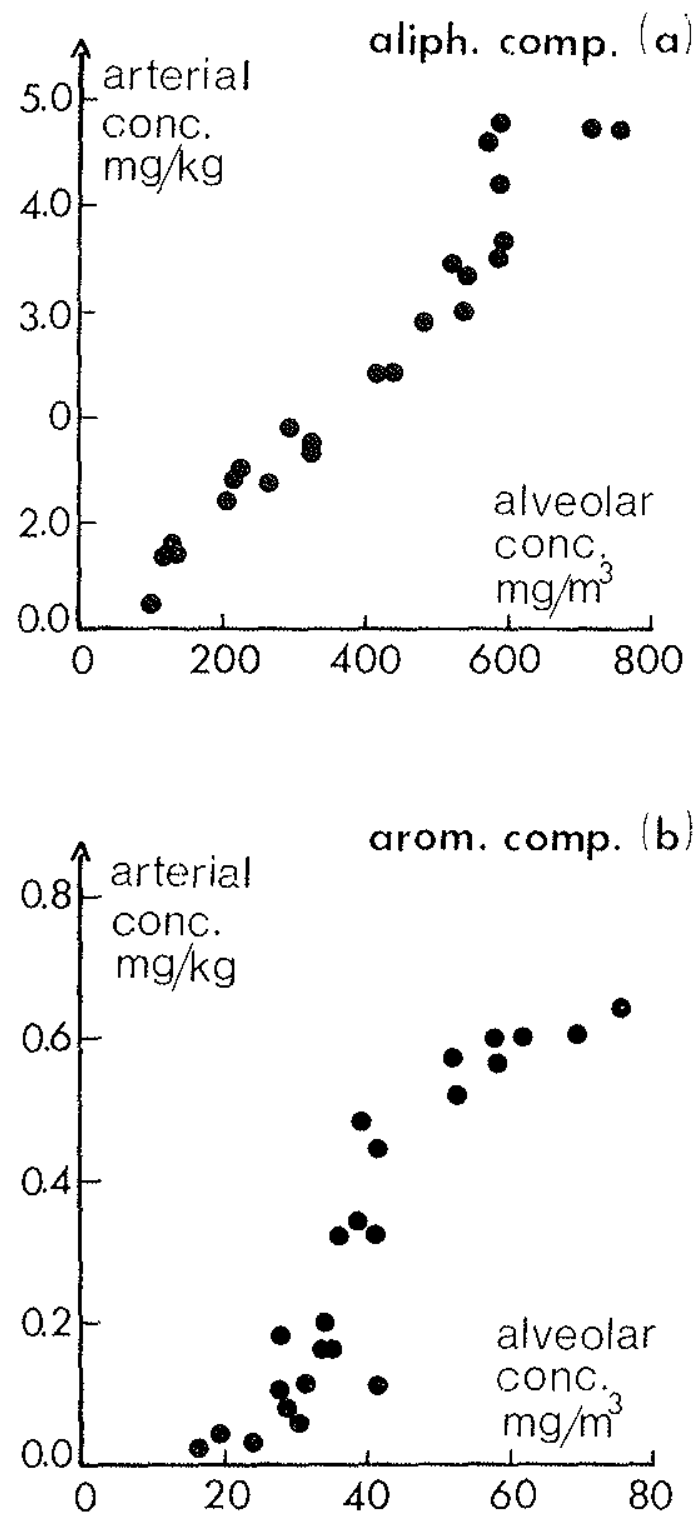

Fig. 2. The relationship between the concentration of aliphatic (a) and aromatic (b) components of white spirit in alveolar air and arterial blood. Data are from one subject. [Product moment correlation: $r=0.940$ (a), $r=$ 0.924 (b))

\section{Heart rate during exposure}

At given points during each performance test in the first experimental series the subject's heart rate was recorded. No difference in heart rate could be noted in trials with and without exposure to white spirit. In other respects heart rate during 


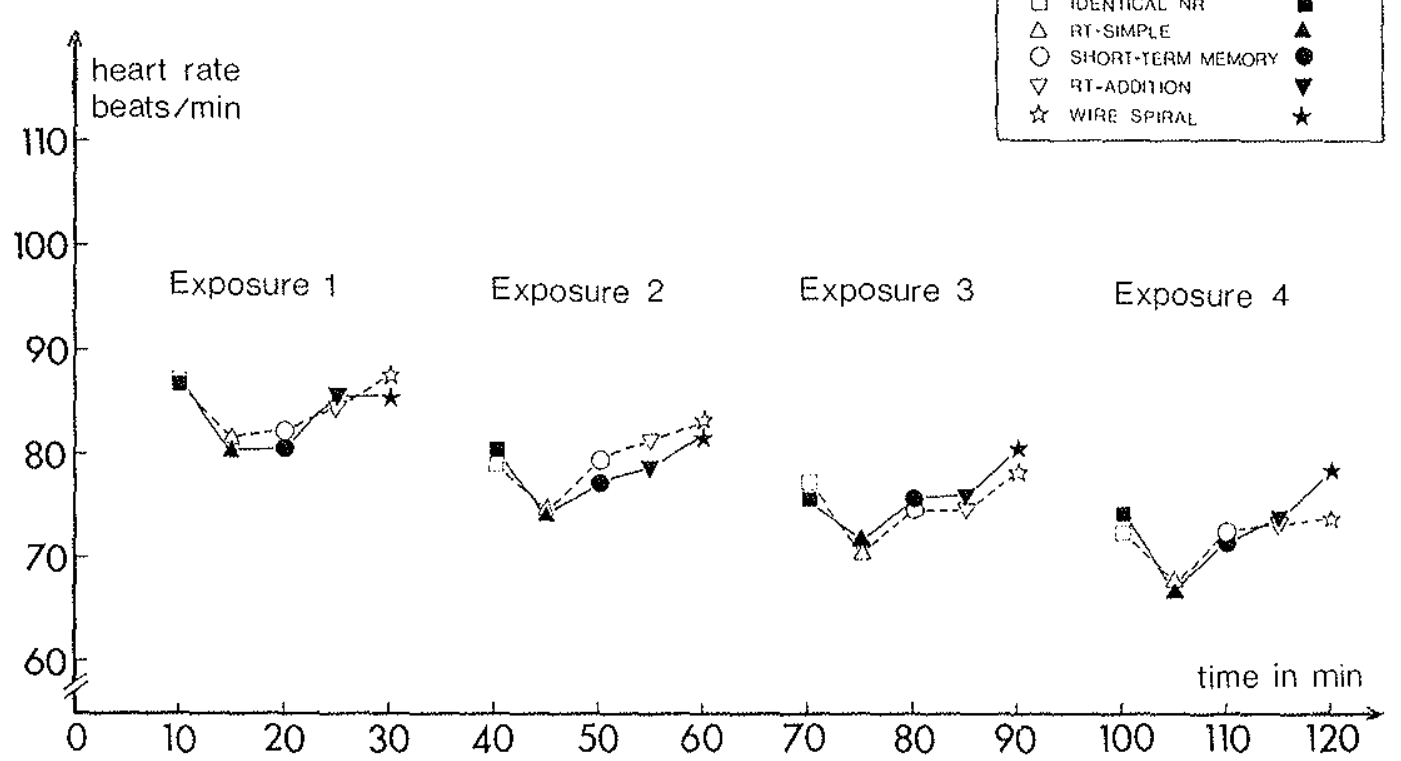

Fig. 3. Heart rate in different performance tests during exposure to white spirit and during control conditions. The symbols in the figure indicate mean values for 14 persons.

experiments displayed variations of the same nature as in the previous studies of the solvents toluene, methylchloroform, and styrene $(2,3,4)$. Thus a systematic decline in heart rate was also found in the present study in repeated tests using the same performance test, and heart rate varied as a function of the character of performance tests. This is readily apparent in fig. 3 in which heart rate on the different measurement occasions displayed the same mutual relationship between the five performance tests.

\section{Performance changes during exposure}

Table 1 and figs. 4 through 6 show the results of performance tests during experimental and control conditions in the first series of trials. Figs. 4-6 show that the change in mean performance values in the different performance tests during exposure to the increasing white spirit concentrations failed to differ systematically from the change under control conditions. A test of the significance of the performance differences between experimental and control conditions in each exposure period disclosed low, nonsignificant $t$ values $(p>0.10)$ for all tests. Thus exposure conditions in the first experimental sexies failed to produce any impairment of performance in the exposed group of subjects.

Table 2 shows the results of the second series of experiments. As shown in table 2 the difference between conditions was statistically significant for the Simple Reaction Time test $(t=2.50 ; \mathrm{p}<0.05)$. When a $10 \%$ significance criterion was applied, the difference between conditions was even significant for the second criterion of the Short-Term Memory test $(t=$ $2.16 ; 0.05<\mathrm{p}<0.10$ ). Thus exposure conditions in the second experimental series produced an increase in reaction time and probable impairment of short-term memory in the exposed group of subjects.

\section{DISCUSSION}

In our previous investigations on solvents $(2,3,4)$ performance changes were studied during exposure to levels of concentration near the threshold limit value for each substance. Since there is no threshold limit value for white spirit, exposure 
Table 1. Mean values and standard deviations for performance tests by 14 subjects with vary. ing degrees of exposure to white spirit and under control conditions.

\begin{tabular}{|c|c|c|c|c|c|c|c|c|}
\hline \multirow{3}{*}{ Performance test } & \multicolumn{8}{|c|}{ Control conditions } \\
\hline & \multicolumn{2}{|c|}{$\begin{array}{c}\text { Exposure } 1 \\
\text { Air }\end{array}$} & \multicolumn{2}{|c|}{$\begin{array}{l}\text { Exposure } 2 \\
\text { Air: }\end{array}$} & \multicolumn{2}{|c|}{$\begin{array}{c}\text { Exposure } 3 \\
\text { Aix }\end{array}$} & \multicolumn{2}{|c|}{$\begin{array}{c}\text { Exposure } 4 \\
\text { Air }\end{array}$} \\
\hline & $\mathrm{M}$ & $\mathrm{SD}$ & $\mathrm{M}$ & $\mathrm{SD}$ & $m$ & $\mathrm{SD}$ & $M$ & $\mathrm{SD}$ \\
\hline \multicolumn{9}{|l|}{ Identical } \\
\hline $\begin{array}{l}\text { Simple Reaction } \\
\text { Time (msec) }\end{array}$ & 238 & 35.5 & 245 & 38.2 & 252 & 44.3 & 24.1 & 39.5 \\
\hline $\begin{array}{l}\text { Short-Term } \\
\text { Memory } \\
\text { (criterion I) a } \\
\text { (criterion II) }\end{array}$ & $\begin{array}{l}81.1 \\
41.7\end{array}$ & $\begin{array}{l}10.9 \\
18.8\end{array}$ & $\begin{array}{l}85.0 \\
52.4\end{array}$ & $\begin{array}{l}10.0 \\
23.0\end{array}$ & $\begin{array}{l}85.8 \\
53.8\end{array}$ & $\begin{array}{l}10.3 \\
26.0\end{array}$ & $\begin{array}{l}88.9 \\
60.8\end{array}$ & $\begin{array}{r}8.0 \\
26.1\end{array}$ \\
\hline $\begin{array}{l}\text { RT Additions } \\
\text { (sec) }\end{array}$ & 1.88 & 0.48 & 1.62 & 0.49 & 1.63 & 0.54 & 1.59 & 0.52 \\
\hline \multirow[t]{2}{*}{$\begin{array}{l}\text { Wire Spiral } \\
\text { (sec) }\end{array}$} & 275 & 78.6 & 253 & 61.7 & 242 & 57.3 & 236 & 49.4 \\
\hline & \multicolumn{8}{|c|}{ Experimental conditions } \\
\hline Performance test & \multicolumn{2}{|c|}{$\begin{array}{c}\text { Exposure } 1 \\
625 \pm 50 \mathrm{mg} / \mathrm{m}^{3}\end{array}$} & \multicolumn{2}{|c|}{$\begin{array}{c}\text { Exposure } 2 \\
1,250 \pm 30 \mathrm{mg} / \mathrm{m}^{3}\end{array}$} & \multicolumn{2}{|c|}{$\begin{array}{c}\text { Exposure } 3 \\
1,875 \pm 60 \mathrm{mg} / \mathrm{m}^{3}\end{array}$} & \multicolumn{2}{|c|}{$\begin{array}{c}\text { Exposure } 4 \\
2,500 \pm 50 \mathrm{mg} / \mathrm{m}^{3}\end{array}$} \\
\hline $\begin{array}{l}\text { Identical } \\
\text { Numbers (min) }\end{array}$ & 6.34 & 1.64 & 5.94 & 1.19 & 6.11 & 1.37 & 599 & 154 \\
\hline $\begin{array}{l}\text { Simple Reaction } \\
\text { Time (msec) }\end{array}$ & 240 & 36.6 & 251 & 45.1 & 248 & 44.1 & 248 & 45.6 \\
\hline $\begin{array}{l}\text { Short-Term } \\
\text { Memory } \\
\text { (criterion I) a } \\
\text { (criterion II) }\end{array}$ & $\begin{array}{l}80.6 \\
50.5\end{array}$ & $\begin{array}{l}12.9 \\
22.9\end{array}$ & $\begin{array}{l}85.4 \\
54.2\end{array}$ & $\begin{array}{r}9.9 \\
26.4\end{array}$ & $\begin{array}{l}85.8 \\
56.7\end{array}$ & $\begin{array}{l}11.7 \\
27.1\end{array}$ & $\begin{array}{l}86.4 \\
56.7\end{array}$ & $\begin{array}{l}11.2 \\
25.0\end{array}$ \\
\hline $\begin{array}{l}\mathrm{RT} \text { Additions } \\
(\mathrm{sec})\end{array}$ & 1.98 & 0.64 & 1.78 & 0.57 & 1.68 & 0.51 & 1.71 & 0.65 \\
\hline $\begin{array}{l}\text { Wire Spiral } \\
\text { (sec) }\end{array}$ & 261 & 49.5 & 251 & 34.4 & 240 & 31.3 & 233 & 29.8 \\
\hline
\end{tabular}

a Criterion $I=$ the number of correctly reproduced stimuli as a percentage of the total number of stimuli; criterion II = the number of correctly reproduced sexies as a percentage of the total number of series.

levels were chosen for the trials within a relatively wide range, and concentrations varied from 625 to $4,000 \mathrm{mg} / \mathrm{m}^{3}$.

As in the previous studies of solvents the measures adopted to disguise exposure proved to be effective. No unequivocal, subjective symptoms were noted by the exposed subjects, who were also unable to distinguish exposure from control conditions. The absence of adverse reactions in the psychological experiments was unexpected, since patently negative reactions were observed in most subjects in conjunction with the physiological experi- ments. The reason for these apparently contradictory results is probably to be found in a combination of circumstances. The experimental situation as a whole, including blood sampling via catheters in veins and arteries, exercise on a bicycle ergometer, and awareness of being exposed, may have contributed to the genesis and reports of symptoms in the physiological trials. Another and probably more decisive factor was the circumstance that the concentrations of white spirit components in alveolar air and arterial blood were greatly affected by the physical 

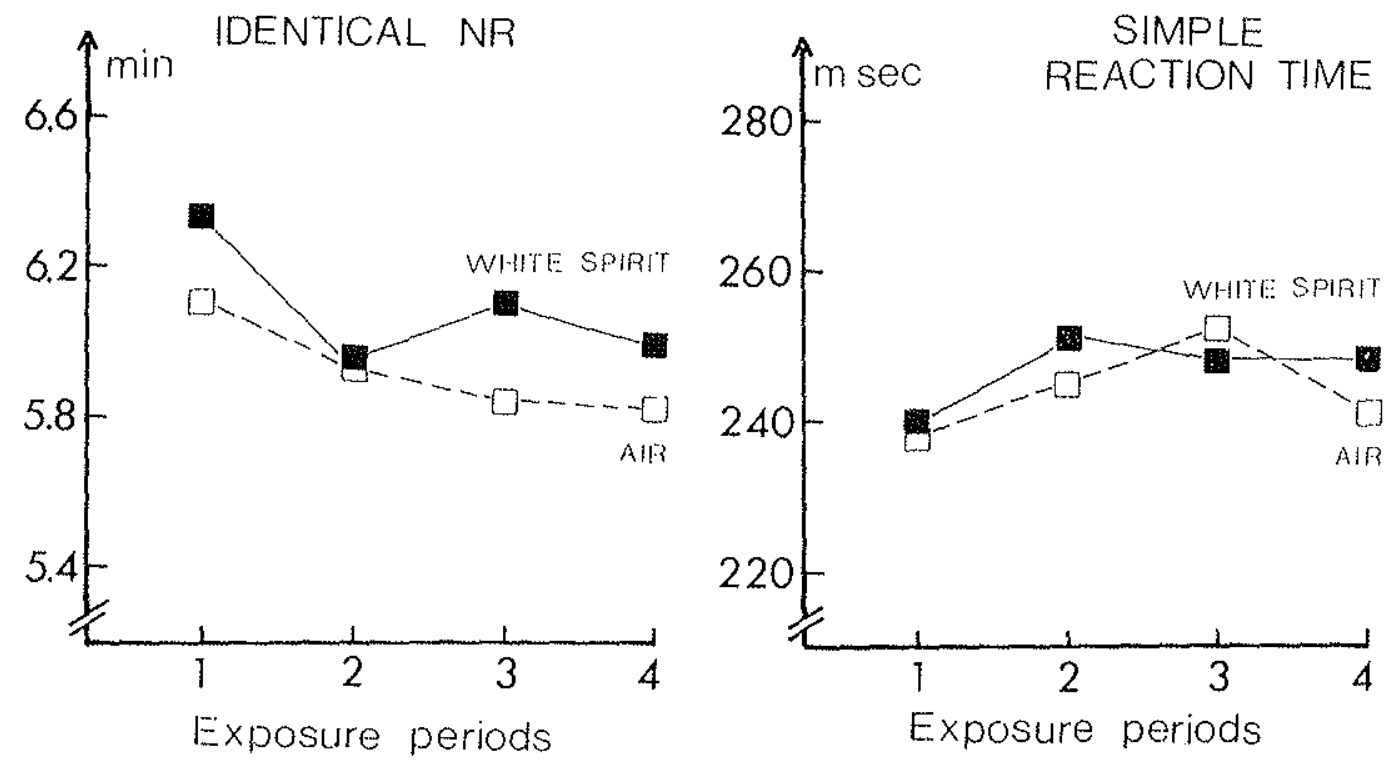

Fig. 4. Changes in mean performance values on the Identical Numbers test and the Simple Reaction Time test at varying degrees of exposure to white spirit. Data taken from table 1.
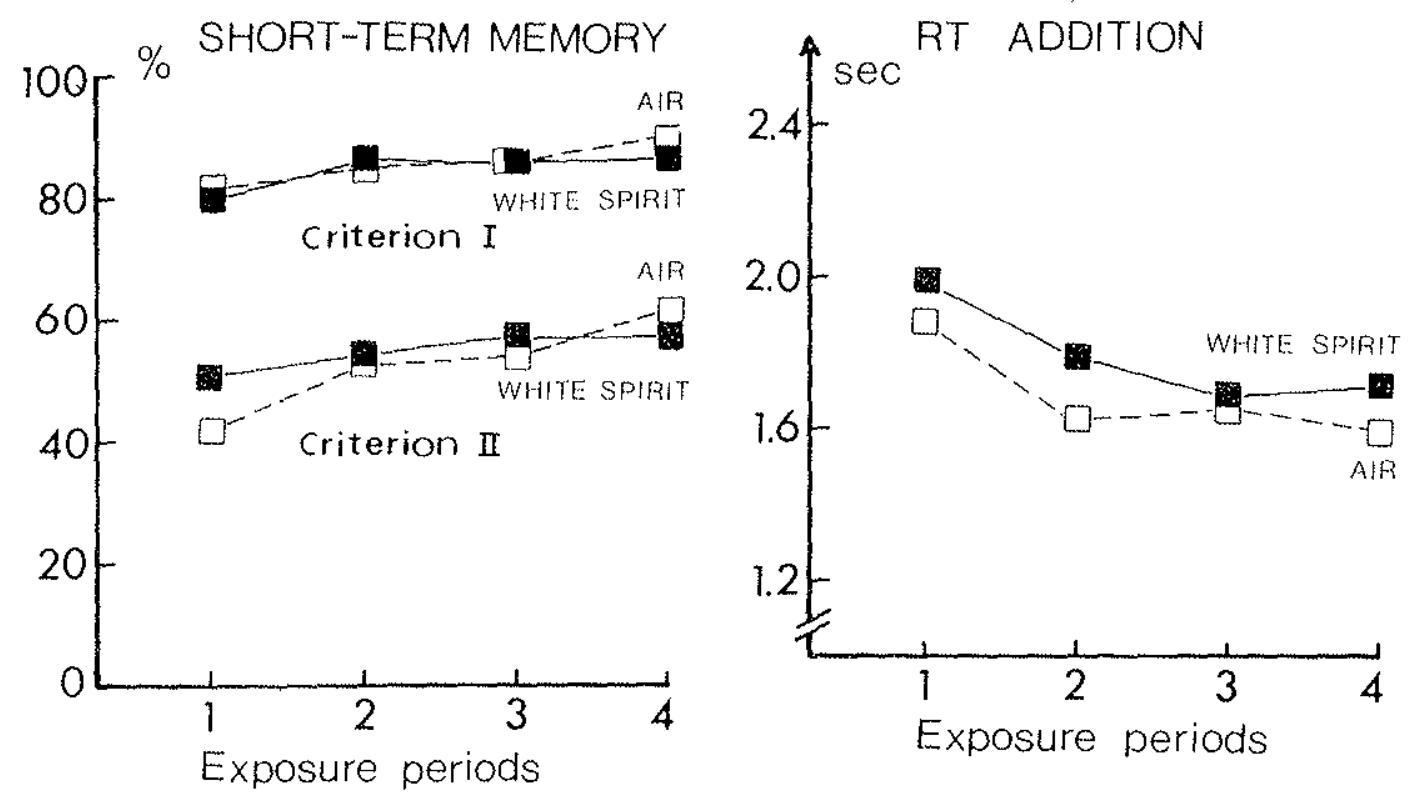

Fig. 5. Changes in mean performance values on the Short-rerm Memory test and the RT Additions test at varying degrees of exposure to white spirit. Data taken from table 1.

exercise (1). Thus the concentration of white spirit in alveolar air was higher in exercise on a bicycle ergometer at an exposure of $2,500 \mathrm{mg} / \mathrm{m}^{3}$ than in exposure to $4,000 \mathrm{mg} / \mathrm{m}^{3}$ during the psychological trials. The latter result is of great importance in determining the level at which white spirit can have an effect on man's psychomotor and intellectual functions.

A prolonged reaction time and probably an impaired short-term memory for visual stimuli were observed after 35 to 40 minutes of exposure to $4,000 \mathrm{mg} / \mathrm{m}^{3}$ of white spirit in inspiratory air. No effect 
Table 2. Mean values, standard deviations, and $t$ values for the differences between the mean values of different performance tests by 8 subjects. The $t$ values were calculated for intrapair mean differences.

\begin{tabular}{|c|c|c|c|c|c|}
\hline \multirow[t]{2}{*}{ Performance test } & \multicolumn{2}{|c|}{$\begin{array}{l}\text { Control } \\
\text { conditions } \\
\text { Air }\end{array}$} & \multicolumn{2}{|c|}{$\begin{array}{c}\text { Experimental } \\
\text { conditions } \\
4,000 \pm 50 \mathrm{mg} / \mathrm{m}^{3}\end{array}$} & \multirow[t]{2}{*}{$\begin{array}{l}t \text { values } \\
\mathrm{M}_{(}-\mathrm{M}_{\mathrm{l}}\end{array}$} \\
\hline & $\mathrm{M}$ & SD & M & $\mathrm{SD}$ & \\
\hline Identical Numbers (min) & 5.95 & 1.03 & 6.32 & 1.42 & -1.32 \\
\hline Simple Reaction Time (msec) & 221 & 29.8 & 233 & 31.0 & $-2.50 \mathrm{a}$ \\
\hline $\begin{array}{l}\text { Short-Term Memory } \\
\text { (criterion I) b } \\
\text { (criterion II) }\end{array}$ & $\begin{array}{l}85.8 \\
58.8\end{array}$ & $\begin{array}{l}6.81 \\
15.5\end{array}$ & $\begin{array}{l}83.9 \\
48.8\end{array}$ & $\begin{array}{l}9.22 \\
21.7\end{array}$ & $\begin{array}{l}1.14 \\
2.16\end{array}$ \\
\hline RT Additions (sec) & 1.69 & 0.48 & 1.62 & 0.62 & 1.00 \\
\hline Wire Spiral (sec) & 205 & 27.1 & 210 & 31.4 & -0.66 \\
\hline
\end{tabular}

a $\mathrm{p}<0.05 ; \quad$ df $=7$

b Criterion $I=$ the number of correctly reproduced stimuli as a percentage of the total number of stimuli; criterion $I Y=$ the number of correctly reproduced series as a percentage of the total number of series.

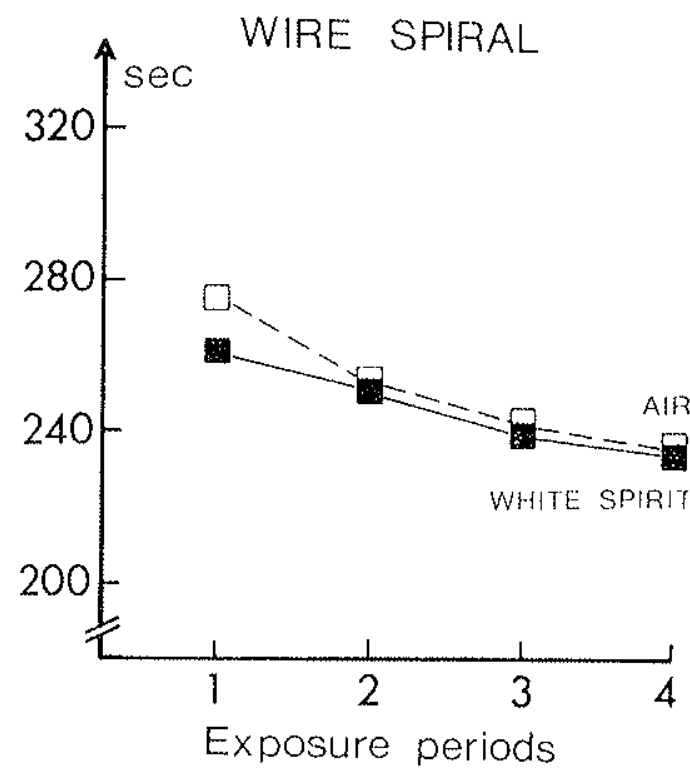

Fig. 6. Changes in mean performance values on the Wire Spiral test at varying degrees of exposure to white spirit. Data taken from table 1.

on functions, such as perceptual speed, numerical ability, and manual dexterity, was found at the same concentration. The aforementioned psychomotor functions, even comprising reaction time and shori... term memory, remained unaffected by exposure to $625,1,250,1,850$, and 2,500 $\mathrm{mg} / \mathrm{m}^{3}$ of white spirit during four continuous 30-minute periods.

The results of the study as a whole lead to the following conclusion: There is obvious risk of subjective distress and an adverse effect on psychomotor and intellectual functions in a worker exposed to $2,500 \mathrm{mg} / \mathrm{m}^{3}$ of white spirit. This view is based on the assumption that physical exertion is a normal feature of most of the work sites at which exposure may occur.

\section{REFERENCES}

1. ASTRAND, I., KILBOM, \&. and OVRUM, P. Exposure to white spirit: I. Concentration in alveolar air and blood during rest and exercise. Scand. $j$. work environ heaith 1 (1975) $15-30$

2. GAMBERALE, F. and HULTENGREN, M. Toluene exposure: II. Psychophysiological functions. Work-environ.-health 9 (1972) $131-139$.

3. GAMBERALE, F. and HULTENGREN, M Methylchloroform exposure: II. Psycho. physiological functions. Work-environhealth 10 (1973) 82-92.

4. GAMBERALE, F, and HULTENGREN, M Exposure to styrene: II. Psychophysiological functions. Work-environ-health 11 (1974) $86-93$

5. SIEGEL, S. Nonparametric statistics for the behavioural sciences. McGraw-Hill Book Co., Tokyo 1956, p. 75.

Received for publication: $1974-10-11$ 